\title{
Developmental picture norms: Relationships between name agreement, familiarity, and visual complexity for child and adult ratings of two sets of line drawings
}

\author{
STEVEN BERMAN, DAVID FRIEDMAN, and MARLA HAMBERGER \\ New York State Psychiatric Institute, New York, New York \\ and \\ JOAN GAY SNODGRASS \\ New York University, New York, New York
}

\begin{abstract}
Developmental differences in name agreement, familiarity, and visual complexity in response to line drawings of common objects were obtained from children and adults. Sixty-one pictures were taken from the Peabody Picture Vocabulary Test-Revised and 259 pictures were taken from the set normed for adults by Snodgrass and Vanderwart (1980). Although there were some differences between the two sets of pictures, the present results replicated the relative independence of these three measures, which was reported by Snodgrass and Vanderwart for adults. Children and adults showed substantial agreement on the names of the pictures. Although the children's ratings were lower on all measures, the differences were trivial for most pictures. We concluded that judgments of familiarity, complexity, and the names of line drawings of common objects are based primarily on information processing accomplished prior to age 7 .
\end{abstract}

Cognitive psychologists have shown an increasing interest in the operations involved in the encoding, storage, and retrieval of pictorial stimuli. Snodgrass and Vanderwart (1980) addressed the paucity of well-characterized experimental picture sets by developing and norming a set of 260 line drawings of familiar concepts.

Developmental investigations would also benefit from the use of standardized picture stimuli. For instance, Hitch and Halliday (1983) and Hulme, Silvester, Smith, and Muir (1986) studied the word-length effect, whereby longer words and their pictured symbols are recalled less often than their shorter counterparts (Schiano \& Watkins, 1981). Hitch and Halliday found that 6-year-olds did not exhibit this effect for pictures, whereas Hulme et al. reported the effect in children as young as 4 years old. However, Hitch and Halliday used a set of line drawings as their stimuli, whereas Hulme et al. chose color pictures taken from prereading books commonly used by young children. Clearly, it would help in interpreting studies like these if the same set of pictorial stimuli were employed, and if the attributes of those stimuli that might be rele-

The authors wish to thank Charles L. Brown for computer programming, and Barry Dunayer and Margaret Cramer for data collating. The research reported here was supported in part by Grant HD14959 from the USPHS to David Friedman, Grant MH30906 to the Psychiatric Institute Computer Center, and by the New York State Department of Mental Hygiene; David Friedman was also supported in part by Research Scientist Development Award K02 MH00510 from NIMH. Address correspondence to Steven Berman, Medical Genetics (A310), New York State Psychiatric Institute, 722 West 168 Street, New York, NY 10032. vant to their memorability were developmentally wellcharacterized.

We undertook a developmental investigation of brain electrical activity in response to visually presented nouns and their pictorial representations. We used the set of 260 line drawings developed by Snodgrass and Vanderwart (1980) and additional stimuli taken from the Peabody Picture Vocabulary Test-Revised (PPVT-R) (Dunn \& Dunn, 1981). Because the youngest experimental group in our study consisted of second- through fourth-grade students, it was important to obtain normative data on the attributes of the stimuli for this age group. Since such data did not previously exist, we collected name agreement, familiarity, and visual complexity norms from 7-10-year-olds for the Snodgrass and Vanderwart picture set, and for adults and children on the pictures taken from the PPVT-R. Although the PPVT-R pictures are black-on-white line drawings superficially very similar to those constructed by Snodgrass and Vanderwart, our analyses show somewhat different characteristics in regard to the relationships between variables. Therefore, we will present the results separately for the two picture sets before reporting on a joint analysis.

\section{METHOD}

\section{Subjects}

Adults

Two college laboratory classes (Class $1=20$ students, Class $2=17$ students) in experimental psychology par- 
ticipated. Mean age of the subjects (14 male) was 29.1 years $(S D=7.8)$. Although 6 additional students were tested, their data were not included because they learned English as adults.

\section{Children}

Forty paid volunteers in second through fourth grade were recruited from the Columbia Presbyterian Medical Center community and by an advertisement in a local paper. Mean age was 8.7 years $(S D=.96)$, with 14 second-graders (6 male), 8 third-graders ( 3 male), and 18 fourth-graders (8 male). All subjects were native English speakers who read at grade level or above. Informed consent was obtained from all children and parents.

\section{Stimuli}

\section{Adults}

Sixty-nine pictures were selected from the PPVT-R according to the following criteria: (1) they were unambiguous drawings of fairly well-known objects, and (2) they did not represent a concept found in the pictures of Snodgrass and Vanderwart (1980). All of the drawings were presented as slides. After presentation to the first adult class, the eight slides that produced the lowest name agreement were dropped, leaving a total of 61 pictures.

\section{Children}

With the exclusion of the picture of the accordion, the 259 pictures used as the core picture set were those developed by Snodgrass and Vanderwart (1980). ${ }^{1}$ The 61 pictures from the PPVT-R used for the adult subjects were added to the core picture set, for a total of 320 stimuli.

\section{Procedure}

\section{Adults}

The pictures were projected in a randomized sequence on a large white screen using a Kodak Carousel slide projector. Presentation time was approximately $15 \mathrm{sec}$, but this was modified as needed to give all subjects ample time to complete the questions.

We used the identical instructions published by Snodgrass and Vanderwart (1980) in order to obtain analogous information from our sample. The subjects were asked to write the first name that came to mind when they viewed a slide, and were told that a name could consist of more than one word. They were told to write "DKO" if they did not recognize what a pictured object was, "DKN" if they did not know the name of the object, and "TOT", (tip-of-the-tongue) if they momentarily could not retrieve the name.

After writing either the name or one of the three failureto-name codes, the subjects were asked to rate the familiarity and visual complexity of each picture. All ratings were on a five-point integer scale, in which low numbers represented the lowest amount of the rated attribute. For familiarity, the subjects were instructed to rate the pictures "according to how usual or unusual the object is in your realm of experience." The subjects were asked to rate the concept rather than the drawing itself. In contrast, for ratings of visual complexity, the subjects were asked to consider the actual amount of detail and intricacy of the specific drawing they were rating. The slides depicting the bee and the balloon from Snodgrass and Vanderwart (1980) were shown to anchor the top and bottom of the scale, respectively. The second class viewed the slides in the reverse order of the first class.

\section{Children}

The Snodgrass and Vanderwart (1980) pictures were randomly assigned to three, 80 -slide carousels. The additional 61 pictures from the PPVT-R were placed in the first section of the fourth carousel, in the order used for adults. The final 19 positions were occupied by the remaining Snodgrass and Vanderwart pictures. Approximately equal numbers of participants viewed the slides in forward and reverse orders. For those subjects who saw the slides in reverse order, the PPVT-R pictures were in positions 20 through 80 of the first carousel presented.

The subjects were tested in groups of 3 to 7 in a conference room. The pictures were projected sequentially on a large white screen with a Kodak Carousel slide projector. Presentation time was approximately $20 \mathrm{sec}$, but this was modified as needed to give all subjects ample time to complete the questions. All tests were run on weekend mornings, when it was assumed that the children would be best able to attend to the task.

It was necessary to modify the instructions of Snodgrass and Vanderwart (1980) in order to obtain analogous information from the children. Few second-graders understand phrases such as "rate the complexity," "realm of experience," and "degree to which you think about the object." The instructions for name agreement, familiarity, and visual complexity are noted below.

Name agreement. The subjects were instructed to write the single best name of each picture on the corresponding line. They were told that a name could consist of more than one word (e.g., "swimming pool"). If the subjects could not recognize a pictured object, they were told to write "?" If they knew the object, but did not know its name, or momentarily could not think of the name, they were told to write "?name."2

Familiarity. The subjects were instructed to circle "very little," "some," or "a lot" in response to the question, "How much do you see or think about this thing?" They were told that if the pictorial concept was a dog, and they had a pet dog, they should circle "a lot," even though the picture may not look much like their own dog, because the question refers to how much they see or think about any dog. In order to anchor their judgments at the other extreme, the "harp" slide was shown as an example of an object most people do not see or think about very often. However, the children were told that if someone they knew had one of these things, they might want to circle one of the other answers. To reduce the effects of response bias, the subjects were encouraged not to rate all pictures 
using the same one or two points on the scale, but to make sure the most familiar concepts were rated "a lot," the least familiar "very little," and others "some."

Visual complexity. The subjects were asked to circle "easy," "medium," or "hard" in response to the question, "How hard would it be to trace or copy this picture?" If there were a lot of small lines, they were told to circle "hard," even if they were very good at drawing or tracing. They were told to pick "easy" if the picture had very few lines, even if they did not like to draw. The slides of "bee" and "balloon" were shown as examples of hard and easy pictures, respectively.

\section{RESULTS AND DISCUSSION}

\section{Snodgrass and Vanderwart Pictures}

The pictures used by Snodgrass and Vanderwart (1980), along with the name most frequently given by the adultsubject sample, are shown in alphabetical order in Appendix A of that paper. Our sample of children produced the same modal names as the Snodgrass and Vanderwart adults for 245 of the 259 concepts. For each picture, we used a frequency distribution of names, as did Snodgrass and Vanderwart, to generate two measures of name agreement. The familiarity and complexity ratings were assigned numerical scores of 1,3 , and 5 such that high numbers corresponded to high complexity ("hard") and high familiarity ("a lot"). For each picture, the following information was collected: modal name, two measures of name agreement (percentage name agreement and the information statistic, $H$; see Snodgrass \& Vanderwart), and the means and standard deviations for familiarity and visual complexity ratings.

Since our subjects were second- through fourth-graders, American Heritage (Carroll, Davies, \& Richman, 1971) frequency counts for third- and fourth-grade literature were tabled and expressed as occurrences per million words. These frequency-in-print measures are available for the 241 concepts that have single-word names. As in Snodgrass and Vanderwart (1980), the print frequencies were transformed by taking the cube root in order to produce distributions similar to the other variables of interest. Length of modal name in letters was included because it has been shown to be a relevant variable in cognitive developmental research using pictures and words (Hitch \& Halliday, 1983; Hulme et al., 1986). All indexes were computed as in Snodgrass and Vanderwart. More specific criteria for response scoring, along with detailed response information for each item, can be found in Berman, Friedman, Hamberger, and Snodgrass (in press).

Table 1 presents summary statistics for $H$, percentage name agreement, familiarity, complexity, and American Heritage frequency for the children, along with the corresponding information from the adult sample of Snodgrass and Vanderwart (1980). All summary measures showed the children's ratings to be very similar to the adult data, although the children were somewhat higher in print frequencies per million words. This discrepancy can be explained by the shifting distribution of types of words in printed material produced for different age groups; children's literature is composed of more simple, picturable nouns, whereas adults' literature is composed of higher proportions of abstractions and grammatical words, such as conjunctions, that are needed in more complex sentences.

\section{Correlations Among the Measures}

These analyses used the picture as the unit of measurement. To determine if there was any effect of the two orders of slide presentation (forward or reverse), correlations were calculated between the three ratings of the subset of children who received the stimuli in the first (forward) order and the ratings of the subset of children who received the stimuli in reverse order. In this way, 259 pairs of numbers were correlated for each of the three measures. The results showed high agreement, which sug-

Table 1

Summary Statistics for All Variables: Snodgrass and Vanderwart Pictures

\begin{tabular}{|c|c|c|c|c|c|c|c|c|c|c|c|c|c|c|}
\hline & \multicolumn{2}{|c|}{$\begin{array}{c}\text { Name } \\
\text { Agreement (\%) }\end{array}$} & \multicolumn{2}{|c|}{$\begin{array}{c}\text { Name } \\
\text { Agreement }(H)\end{array}$} & \multicolumn{2}{|c|}{ Familiarity } & \multicolumn{2}{|c|}{ Complexity } & \multirow{2}{*}{$\frac{\mathrm{K}-\mathrm{F}}{\text { Adult }}$} & \multirow{2}{*}{$\frac{\text { AH34 }}{\text { Child }}$} & \multirow{2}{*}{$\frac{\text { K-F' }}{\text { Adult }}$} & \multirow{2}{*}{$\frac{\mathrm{AH} 34^{\prime}}{\text { Child }}$} & \multicolumn{2}{|c|}{ Length } \\
\hline & Adult & Child & Adult & Child & Adult & Child & Adult & Child & & & & & Adult & Child \\
\hline$M$ & 83.47 & 83.65 & .558 & .572 & 3.29 & 3.03 & 2.96 & 2.72 & 37.17 & 84.99 & 2.44 & 3.59 & 5.99 & 5.79 \\
\hline$S D$ & 14.43 & 18.67 & .526 & .596 & .96 & .84 & .90 & .87 & 86.89 & 132.90 & 1.59 & 1.80 & 2.45 & 2.31 \\
\hline$M D N$ & 90.00 & 92.50 & .42 & .34 & 3.32 & 3.05 & 2.93 & 2.60 & 12.82 & 41.43 & 2.34 & 3.46 & 5.00 & 5.00 \\
\hline Q1 & 79.00 & 72.50 & .12 & .00 & 2.49 & 2.30 & 2.28 & 2.05 & 3.0 & 13.00 & 1.44 & 2.35 & 4.00 & 4.00 \\
\hline Q3 & 98.00 & 97.50 & .87 & .95 & 4.09 & 3.75 & 3.59 & 3.45 & 32.5 & 90.9 & 3.19 & 4.50 & 7.00 & 7.00 \\
\hline IQR & 19.00 & 25.00 & .75 & .95 & 1.60 & 1.45 & 1.31 & 1.40 & 29.5 & 77.9 & 1.75 & 2.15 & 3.00 & 3.00 \\
\hline \multicolumn{15}{|l|}{ Range: } \\
\hline Min & 33.00 & 25.00 & 0 & 0 & 1.18 & 1.50 & 1.00 & 1.10 & 0 & 0 & 0 & 0 & 3 & 2 \\
\hline $\operatorname{Max}$ & 100.0 & 100.0 & 2.55 & 2.58 & 4.90 & 4.60 & 4.78 & 4.65 & 884.4 & 848.9 & 9.60 & 9.47 & 14 & 13 \\
\hline Skew & -1.37 & -1.27 & 1.01 & 1.11 & .09 & -.04 & .02 & .24 & 5.99 & 3.24 & 1.00 & .73 & .97 & .98 \\
\hline Number of Concepts & 260 & 259 & 260 & 259 & 260 & 259 & 260 & 259 & 241 & 241 & 241 & 241 & 260 & 259 \\
\hline
\end{tabular}

Note-All adult data were calculated from the Snodgrass and Vanderwart (1980) study. Statistics for children are from the current study. Name Agreement $(\%)=$ percentage of responses in agreement with modal name; Name Agreement $(H)=H$ for name agreement; Complexity $=$ visual complexity; AH34 = The American Heritage Word Frequency Book (Carroll et al., 1971) frequencies per million for Grades 3 and 4; AH34' = cube root transformed frequencies; K-F = KuČera-Francis frequencies per million words; $K-F^{\prime}=$ cube root transformed frequencies; $Q 1=25$ th percentile; $\mathrm{Q} 3=75$ th percentile; $\mathrm{IQR}=$ interquartile range. 
Table 2

Significant Correlations Among Measured Variables in Four Studies for All Concepts Possible: Snodgrass and Vanderwart Pictures

\begin{tabular}{|c|c|c|c|c|c|c|}
\hline Variable & & NA (\%) & NA $(H)$ & Complexity & Familiarity & Length \\
\hline Name Agreement $(H)$ & & $\begin{array}{c}-.946 * \\
-.941 \dagger \\
\ldots \neq \\
-.9528\end{array}$ & & & & \\
\hline Visual Complexity & & $\begin{array}{c}-.198 \\
- \\
4 \\
-\end{array}$ & $\begin{array}{c}.225 \\
.130 \\
.157 \\
-\end{array}$ & & & \\
\hline Familiarity & & $\begin{array}{c}.214 \\
- \\
\# \\
-\end{array}$ & $\begin{array}{c}-.168 \\
- \\
- \\
-\end{array}$ & $\begin{array}{l}-.486 \\
-.466 \\
-.457 \\
-.455\end{array}$ & & \\
\hline Length & & $\begin{array}{c}-.386 \\
-.357 \\
\# \\
\#\end{array}$ & $\begin{array}{c}.354 \\
.272 \\
\# \\
\#\end{array}$ & $\begin{array}{c}.202 \\
- \\
\# \\
\#\end{array}$ & $\begin{array}{c}-.161 \\
- \\
\# \\
\#\end{array}$ & \\
\hline $\begin{array}{l}\text { Transformed } \\
\text { Frequency** }\end{array}$ & $\begin{array}{l}\text { (a) } \\
\text { (b) }\end{array}$ & $\begin{array}{c}.418 \\
.193 \\
\# \\
\#\end{array}$ & $\begin{array}{c}-.347 \\
- \\
\# \\
\#\end{array}$ & $\begin{array}{c}- \\
-.180 \\
\# \\
\#\end{array}$ & $\begin{array}{c}.292 \\
.363 \\
\# \\
\#\end{array}$ & $\begin{array}{c}-.532 \\
-.475 \\
\# \\
\#\end{array}$ \\
\hline
\end{tabular}

Note-All listed correlations are significant at $p<.01$. NA = name agreement, $\#=$ not computed, - = not significant. *Current study-USA, children. † Snodgrass and Vanderwart (1980)-USA, adults. $\ddagger$ van Schagen et al. (1983)-Holland, adults. §Matsukawa (1983)-Japan, adults. **Frequencies for line a are from The American Heritage Word Frequency Book (Carroll et al., 1971) for Grades 3 and 4; line b frequencies are from Kucera and Francis (1967). Frequencies were transformed by taking the cube root of the book value expressed as occurrences per million words.

gests little effect of presentation order on measures of percent name agreement $(r=.84)$, familiarity $(r=.80)$, and visual complexity $(r=.87)$. Correlations between the Snodgrass and Vanderwart (1980) adult ratings and our child ratings were high: .70 for percent name agreement, .75 for $H, .89$ for familiarity, and .92 for complexity.

The intercorrelations between the different measures in Snodgrass and Vanderwart's (1980) adult sample and our child sample are given in Table 2 . The pattern of relative independence among the measures reported by Snodgrass and Vanderwart (low intercorrelations with the exception of a moderate negative relationship between familiarity and complexity) was replicated with the children in the present study. This pattern has also been found in two independent adult replications in Japan and Holland (Matsukawa, 1983; van Schagen, Tamsma, Bruggemann, Jackson, \& Michon, 1983), which are also presented in Table 2. As expected, the correlation between the two measures of name agreement in our sample was quite high, as it was in the Snodgrass and Vanderwart adult sample. The consistency of the pattern shown in Table 2 across cultures and age groups enhances the usefulness of the picture set as a tool for cognitive research.

The negative correlation between familiarity and visual complexity is clearly a robust property of this set of pictures. Snodgrass and Vanderwart (1980) discussed the possible reasons for the relationship of visual complexity with the other variables, including the style of the artist, real-life properties of the pictured objects, and a simplified grammar of representation that develops for familiar concepts. It is not possible to choose between these alternatives with this set of data. However, as Snodgrass and Vanderwart implied, it would aid the interpretation of this negative relationship if the ratings were compared with those obtained on another set of stimuli. They report the same pattern of correlations on a subset of the concepts drawn by a different artist. However, the important choices made by both artists in representing each concept may have been guided by similar instructions given by the experimenters. When we collected norms on a similar set of line drawings from the PPVT-R (reported below), the negative correlation between familiarity and complexity vanished.

We also calculated a separate intercorrelation matrix for the concepts for which age-of-acquisition ratings were available. These results are presented, along with those of the other studies that examined this variable, in Table 3. For our sample of children the subset included 88 concepts, whereas Snodgrass and Vanderwart (1980) reported on 89 concepts, and the replication from Holland reported on 135. The correlation of age of acquisition with children's familiarity ratings $(-.61)$ was similar to that of age of acquisition with American Heritage frequency $(-.60)$. A slightly, but not significantly, more negative relationship resulted between age of acquisition and child familiarity $(-.61)$ than with adult familiarity $(-.55)$. 
Table 3

Significant Correlations Among Measured Variables in Three Studies

for the Snodgrass and Vanderwart Concepts for which Judged Age-of-Acquisition Norms Were Available

\begin{tabular}{ccccccc}
\hline Variable & NA $(\%)$ & NA $(H)$ & Complexity & Familiarity & Length & Frequency \\
\hline Name Agreement $(H)$ & $-.951^{*}$ & & & \\
& $-.970 \dagger$ & & & \\
$\# \ddagger$ & & &
\end{tabular}

Visual Complexity

Familiarity

Length $\quad-$.

Transformed

Frequency*

AA

- $\quad$ -

$\begin{array}{ccc}- & - & -.366 \\ - & - & -.413 \\ \# & - & -.5 \\ -.292 & - & \\ - & - & \\ \# & \# & \\ .347 & -.272 \\ - & - & \\ \# & \#\end{array}$

\begin{tabular}{cccc}
-.366 & & & \\
-.413 & & & \\
-.511 & & & \\
- & -.363 & & \\
- & -.284 & & \\
$\#$ & $\#$ & & \\
- & .384 & -.468 & \\
- & .499 & -.411 & \\
$\#$ & $\#$ & $\#$ & \\
.280 & -.606 & .455 & -.599 \\
- & -.550 & .416 & -.482 \\
.300 & -.561 & $\#$ & $\#$ \\
\hline
\end{tabular}

Note-All listed correlation coefficients for the current study and the Snodgrass and Vanderwart study are significant at $p<.01$. All comparable correlation coefficients (those larger than .25 ) are listed for the Van Schagen et al. study. NA = name agreement, $A A=$ age of acquisition, $\#=$ not computed, $-=$ not significant. *Current study. †Snodgrass and Vanderwart (1980). ‡Van Schagen et al. (1983). **Frequencies for children are from The American Heritage Word Frequency Book (Carroll et al., 1971). Those on the second line are from Kuxera and Francis (1967). Frequencies were transformed by taking the cube root of the book value expressed as occurrences per million words.

\section{Factor Analyses of the Data}

To examine the relationships between the variables further, separate factor analyses were performed on the data collected from our children and the corresponding ratings in Snodgrass and Vanderwart's (1980) sample. Since we collected data on three of the Snodgrass and Vanderwart variables, we generated a three-factor solution, using pairwise deletion of cases with missing data. ${ }^{3}$

A varimax rotation was performed to clarify the nature of the factors. As can be seen in Table 4, Factor 1 primarily represents the contribution of the two measures of name agreement for both adults and children. A separate factor represents the measures of picture complexity and familiarity. This was the second factor in the adult sample and the third factor for the children's data. Another factor represents two characteristics of the lexical analog of the picture: word length and the frequency in print indices. This lexical factor was the third factor in adults but the second in the children's data. Age of acquisition also loaded on this factor when it was included in the analysis. However, the age of acquisition correlations were based on a sample size of 88 , which is considerably less than the number of concepts on which the other correlations were based. In the child sample, the second and third factors were reversed, as shown in Table 4.

When a combined factor analysis was performed on the child and adult variables, a solution similar to the separate adult result was generated. In this analysis, there were four variables that loaded highest on the lexical (third) factor: age of acquisition, word length, and transformed print frequencies for children (American Heritage) and adults (Kučera-Francis). Partial correlations of the relationships between these four variables showed that the cohesiveness of the factor depended on the children's, but not the adults', print frequencies. That is, if the three other variables that loaded highest on the lexical factor are correlated with each other after the adult print-frequency variable has been partialed out, the resulting correlations retain significance [child frequency with length $=-.29$

Table 4

Separate Rotated-Factor Matrices for the 260 Concepts in the Adult Sample of Snodgrass and Vanderwart (1980) and in the Current Study of Children

\begin{tabular}{lrrr}
\hline & Factor 1 & Factor 2 & Factor 3 \\
\hline Adult & & & \\
Name (\%) & -.96 & .05 & .18 \\
Name (H) & .98 & -.07 & -.08 \\
Familiarity & -.00 & .84 & .21 \\
Complexity & .10 & -.85 & -.01 \\
Length & .26 & .02 & -.83 \\
Frequency (K-F) & -.00 & .26 & .85 \\
& Factor 1 & Factor 3 & Factor 2 \\
Child & -.94 & -.11 & .25 \\
Name (\%) & .96 & .10 & -.18 \\
Name (H) & -.03 & -.84 & -.22 \\
Familiarity & .15 & .87 & .02 \\
Complexity & .20 & .10 & -.82 \\
Length & -.18 & -.09 & .87 \\
Frequency (AH) & & & \\
\hline
\end{tabular}

Note-K-F = Kuxera and Francis (1967); $\mathrm{AH}=$ The American Heritage Word Frequency Book (Carroll et al., 1971). 
$(p<.001)$, child frequency with age of acquisition $=-.38$ $(p<.001)$, and age of acquisition with length $=.26$ $(p<.02)$ ]. If the children's print frequency is partialed out instead, not one of the correlations approaches significance. This reflects the fact that children not only learn shorter words first, but that children's literature tends to favor precisely those short words most familiar to children. Therefore, the fact that child print frequencies are superior to adult print frequencies as predictors of ageof-acquisition scores suggests that these scores do indeed index childhood memories more than adult memories (adult memories are more current, since adults produced the age-of-acquisition ratings), which increases confidence in the validity of this measure.

To summarize our findings, we found that ratings of name agreement, familiarity, and visual complexity of 259 line drawings of Snodgrass and Vanderwart (1980) show substantial agreement between college students and secondthrough fourth-graders. The pattern of relationships between these variables reported by Snodgrass and Vanderwart was particularly robust, and was replicated both in our sample of children and in adult samples from Japan and Holland (Matsukawa, 1983; van Schagen et al., 1983). Our data tend to validate the age-of-acquisition measure of Carroll and White (1973a, 1973b). These findings emphasize the importance of early learning as a determinant of adult ratings, and increase the utility of the Snodgrass and Vanderwart drawings as experimental stimuli for developmental investigations.

\section{Peabody Pictures}

The pictorial representations of the 61 concepts, numbered in alphabetical order according to the modal name produced by adults, are presented in the appendix. The normative data on the individual pictures and detailed naming information for both age groups can be found in Berman et al. (in press). The Kučera-Francis (1967) wordfrequency count was used for the adults, and the Ameri- can Heritage Word Frequency Book (Carroll et al., 1971) counts for Grades 3 and 4 were used for the children in our study.

Table 5 presents summary statistics for $H$, percentage name agreement, familiarity, complexity, word length, and print frequency, along with the cube root of the frequencies. Child and adult summary measures are very similar, although the print counts based on children's literature were higher than the adult counts, which reflects the greater representation of concrete picturable nouns in material read by children.

\section{Correlations Among the Measures}

To determine the effects of order of slide presentation, correlations were calculated between the ratings of the two groups who received the stimuli in forward and reverse sequence. The results for adults showed high agreement, which represents little effect of presentation order on measures of percent name agreement $(r=.86)$, familiarity $(r=.87)$, and visual complexity $(r=.71)$. For the children, the corresponding correlations were $r=.85$, $r=.68$, and $r=.87$, even though the items were near the beginning or end of a much longer sequence. The correlations between the adult and child ratings were high: .70 for percent name agreement, .69 for $H, .82$ for familiarity, and .89 for complexity.

The intercorrelations between the different measures are given in Table 6 . The pattern of relative independence among directly rated measures reported for the Snodgrass and Vanderwart (1980) pictures was even more marked for the current picture set. Besides the expected high correlation between percentage name agreement and the $H$ statistic, children, but not adults, showed a low to moderate positive correlation between percent name agreement and familiarity. This correlation reflects the higher name agreement associated with more familiar words in children. There was also a low to moderate positive correlation between word length and visual complexity in children, and

Table 5

Summary Statistics for All Variables for 61 PPVT-R Pictures in Adults and Children

\begin{tabular}{|c|c|c|c|c|c|c|c|c|c|c|c|c|c|c|}
\hline & \multicolumn{2}{|c|}{$\begin{array}{c}\text { Name } \\
\text { Agreement (\%) }\end{array}$} & \multicolumn{2}{|c|}{$\begin{array}{c}\text { Name } \\
\text { Agreement }(H)\end{array}$} & \multicolumn{2}{|c|}{ Familiarity } & \multicolumn{2}{|c|}{ Complexity } & \multirow{2}{*}{$\frac{\mathrm{K}-\mathrm{F}}{\text { Adult }}$} & \multirow{2}{*}{$\frac{\text { AH34 }}{\text { Child }}$} & \multirow{2}{*}{$\frac{K-F^{\prime}}{\text { Adult }}$} & \multirow{2}{*}{$\frac{\text { AH34' }}{\text { Child }}$} & \multicolumn{2}{|c|}{ Length } \\
\hline & Adult & Child & Adult & Child & Adult & Child & Adult & Child & & & & & Adult & Child \\
\hline $\bar{M}$ & 67.44 & 61.39 & 1.10 & 1.29 & 2.82 & 2.74 & 3.04 & 3.16 & 14.18 & 44.70 & 1.71 & 2.66 & 7.23 & $6 . \overline{71}$ \\
\hline$S D$ & & 26.43 & .1 & .88 & .78 & .60 & .66 & .70 & 26.07 & 123.40 & 1.27 & .54 & 11 & 16 \\
\hline$M D N$ & 70.30 & 67.50 & 1.00 & 1.20 & 2.59 & 2.70 & 3.00 & 3.15 & 4.44 & 14.22 & 1.64 & 2.42 & 7.00 & 6.00 \\
\hline Q1 & 48.6 & 42.5 & .40 & .60 & 2.17 & 2.32 & 2.59 & 2.75 & 1.0 & 3.7 & 1.00 & 1.55 & 5.00 & 5.00 \\
\hline Q3 & 86.5 & 80.0 & 1.60 & 2.00 & 3.30 & 3.10 & 3.62 & 3.82 & 14.8 & 32.8 & 2.45 & 3.20 & 9.00 & 8.00 \\
\hline IQR & 37.9 & 37.5 & 1.20 & 1.40 & 1.13 & .78 & 1.03 & 1.07 & 13.8 & 29.1 & 1.45 & 1.65 & 4.00 & 3.00 \\
\hline \multicolumn{15}{|l|}{ Range: } \\
\hline Min & .00 & 5.00 & .00 & .00 & 1.67 & 1.53 & 1.78 & 1.76 & .00 & .62 & .00 & .85 & 3.00 & 3.00 \\
\hline $\operatorname{Max}$ & 97.30 & 100.0 & 3.50 & 3.38 & 4.49 & 4.05 & 4.32 & 4.31 & 159.73 & 821.07 & 5.43 & 9.36 & 14.00 & 14.00 \\
\hline Skew & -.60 & -.24 & .74 & .31 & .68 & .38 & -.01 & -.20 & 3.83 & 5.73 & .52 & 2.16 & .54 & .73 \\
\hline Number of Concepts & 61 & 61 & 61 & 61 & 61 & 61 & 61 & 61 & 52 & 47 & 52 & 47 & 61 & 61 \\
\hline
\end{tabular}

Note-All adult data were calculated from the Snodgrass and Vanderwart (1980) study. Statistics for children are from the current study. Name Agreement $(\%)=$ percentage of responses in agreement with modal name; Name Agreement $(H)=H$ for name agreement; Complexity $=$ visual complexity; AH34 = The American Heritage Word Frequency Book (Carroll et al., 1971) frequencies per million for Grades 3 and 4; AH34' = cube root transformed frequencies; $K-F=$ Kucera-Francis frequencies per million words; $K-F^{\prime}=$ cube root transformed frequencies; $Q 1=25$ th percentile; $\mathrm{Q3}=75$ th percentile; $\mathrm{IQR}=$ interquartile range. 
Table 6

Significant Correlations Among Measured Variables in Adults and Children for All 61 PPVT-R Concepts

\begin{tabular}{|c|c|c|c|c|c|c|c|c|c|c|}
\hline \multirow[b]{2}{*}{ Variable } & \multicolumn{2}{|c|}{ NA (\%) } & \multicolumn{2}{|c|}{ NA $(H)$} & \multicolumn{2}{|c|}{ Complexity } & \multicolumn{2}{|c|}{ Familiarity } & \multicolumn{2}{|c|}{ Length } \\
\hline & Adults & Children & Adults & Children & Adults & Children & Adults & Children & Adults & Children \\
\hline Name Agreement $(H)$ & -.773 & -.946 & & & & & & & & \\
\hline Visual Complexity & - & - & - & - & & & & & & \\
\hline Familiarity & - & .364 & - & - & - & - & & & & \\
\hline $\begin{array}{l}\text { Length } \\
\text { Transformed }\end{array}$ & - & - & - & - & - & .355 & - & - & & \\
\hline Frequency* & - & - & - & - & - & - & - & - & -.402 & - \\
\hline
\end{tabular}

Note-All listed correlations are significant at $p<.01 . \mathrm{NA}=$ name agreement, $-=$ not significant. For print frequency, correlations are based on only 49 concepts for adults and 54 for children due to two-word names. * Frequencies for children were calculated using The American Heritage Word Frequency Book (Carroll et al., 1971) for Grades 3 and 4 . Adult frequency figures are from Kucera and Francis (1967). Frequencies were transformed by taking the cube root of the book value expressed as occurrences per million words.

a moderate negative correlation between word length and transformed frequency in adults. The latter correlation may result from the tendency to use shortened names, such as TV, for familiar objects in the written literature.

Conspicuously absent in the data was the moderate negative correlation between complexity and familiarity shown reliably for the Snodgrass and Vanderwart (1980) pictures with adults and in the current study with children. For the Peabody pictures, the correlation for children was close to zero $(r=-.05)$, and adults produced a nonsignificant correlation in the opposite direction $(r=+.17)$. A partial explanation of this difference derives from the more restricted range and lower variability of the complexity ratings of the PPVT-R pictures. Whereas Snodgrass and Vanderwart instructed their artists to vary the size and detail of the drawings as a function of the real-life characteristics of the pictured objects, the Peabody pictures were specifically drawn to minimize variation in size and complexity (Dunn \& Dunn, 1981, p. 31).

Although the real-life characteristics of the pictured objects are still likely to find representation in the drawings (see the appendix), the PPVT-R subset we selected had a visual complexity range of 1.8-4.0 $(S D=.7)$, compared to a range of 1.0-4.8 $(S D=.9)$ in the Snodgrass and Vanderwart (1980) pictures. If the inverse relationship between familiarity and complexity was indeed produced by the real-life properties of the pictured objects, then the amount of freedom to portray visual complexity was insufficient to demonstrate this relationship in the Peabody picture subset we used. Since this subset represents clear line drawings of a fairly wide range of picturable nouns, it cannot be assumed that similar sets of drawings will show the relationship between complexity and familiarity found consistently for the Snodgrass and Vanderwart pictures.

\section{Factor Analyses of the Data}

The variables were subjected to separate factor analyses for adults and children, and three-factor solutions were generated. The results after varimax rotation are presented in Table 7. In the adult data, Factor 1 corresponded to name agreement, Factor 3 included the familiarity and visual-complexity variables, and the lexical variables of word length and print frequency loaded on Factor 2. In the analysis of children's data, the three factors correspond to name agreement, visual complexity/length, and print frequency/familiarity, respectively.

Although the solution for adults was similar to the three factors generated to explain the Snodgrass and Vanderwart (1980) adult data and the data we collected in children, a number of facts indicate that the structure of the relationships between variables is different in response to the two picture sets. The association of familiarity with complexity in adults was a product of the varimax rotation, since the unrotated solution associated complexity with the lexical variables (word length and print frequency), leaving familiarity as the sole variable loading on the third factor. More importantly, the adult-data relationship between familiarity and complexity did not replicate the consistent moderately negative correlation shown for the Snodgrass and Vanderwart pictures, but produced a weak positive correlation. Clearly, these variables are related differently in the two sets of pictures.

To the extent that the present findings can be generalized to the population of Peabody pictures, these stimuli are particularly useful for cognitive experiments that re-

Table 7

Separate Rotated-Factor Loadings for 61 PPVT-R Concepts in the Adult and Child Samples

\begin{tabular}{lrrr}
\hline & Factor 1 & Factor 2 & Factor 3 \\
\hline Adult & & & \\
Name (\%) & -.93 & .13 & .08 \\
Name (H) & .93 & .10 & -.10 \\
Complexity & -.07 & -.25 & .74 \\
Familiarity & -.10 & .18 & .75 \\
Length & .21 & -.78 & .33 \\
Frequency (K-F) & .13 & .85 & .18 \\
Child & & & \\
Name (\%) & .96 & -.10 & .20 \\
Name (H) & -.97 & .07 & -.11 \\
Complexity & .04 & .83 & .07 \\
Length & -.19 & .79 & -.16 \\
Familiarity & .34 & .10 & .58 \\
Frequency (AH) & .02 & -.16 & .89 \\
\hline
\end{tabular}

Note-K-F = Kucera and Francis (1967); $\mathrm{AH}=$ The American Heritage Word Frequency Book (Carroll et al., 1971). 
quire independence of the rated measures and/or large numbers of pictures. Our 61 stimuli represent less than $10 \%$ of the 684 Peabody plates. In addition, since the Peabody plates have been standardized at each of three developmental levels (age 2.5-5, age 5-10, and age 8-adult), some developmental norms already exist to assist the researcher in designing experiments.

\section{Combined Analysis}

A combined analysis of the 259 Snodgrass and Vanderwart (1980) stimuli and the 61 PPVT-R pictures that were presented to children in the present study, along with the corresponding data collected by us from adults for the 61 Peabody pictures, and by Snodgrass and Vanderwart for their 259 pictures, was performed. The correlations between child and adult scores for this combined analysis were .75 for percent name agreement, .76 for $H, .89$ for familiarity, and .91 for complexity.

For the variables of familiarity and complexity, $t$-tests were performed to assess the magnitude of the differences between the two age groups on all 320 items. The 30 largest $t$-values, which represent items that produced differences between the two age groups at approximately the .01 level, are listed in Table 8. The preponderance of positive values (for both variables, 28 out of $30 t$-values are positive) indicates that adults generally produced higher ratings than did children for familiarity and complexity of line drawings of common concepts. However, although the significance of the differences between age groups is large (only 3.2 items would have been expected to reach this level of significance due to chance), the size of the effect was quite small-the distributions of children's and adults' scores overlap about $75 \%$ and the mean difference between groups is only about one fourth of a standard deviation within either group. Therefore, these differences, although real, are trivial for almost all items. Moreover, this finding is primarily due to the subset of items listed in Table 8. For example, it is not surprising that the pictures that represent "ashtray" and "pipe" were more familiar to adults than to children. Furthermore, with the information provided in Berman et al. (in press), the investigator can select stimuli with minimal age-related differences.

To assess the factors that might account for differences in the relationship between the familiarity and complexity ratings found for the two picture sets, this relationship was examined for subsets of the items in each set. Inspection of the items in the appendix shows that some of the PPVT-R pictures have background detail added to the representation of the named object (fern, logs, etc.). This background detail might have led to naming ambiguity and may have altered the negative relationship between familiarity and complexity that is a robust aspect of the

Table 8

The 30 Items Rated Most Differently by Children and Adults

\begin{tabular}{|c|c|c|c|c|c|c|c|}
\hline \multicolumn{4}{|c|}{ Complexity } & \multicolumn{4}{|c|}{ Familiarity } \\
\hline Concept & Adult & Child & $t$ & Concept & Adult & Child & $t$ \\
\hline Axe & 2.48 & 1.80 & 2.69 & Ashtray & 3.56 & 2.00 & 4.93 \\
\hline Ball & 2.28 & 1.65 & 2.71 & Bus & 4.50 & 3.60 & 3.37 \\
\hline Balloon & 1.55 & 1.15 & 3.19 & Comb & 4.52 & 3.45 & 3.61 \\
\hline Baseball bat & 1.20 & 1.90 & -3.14 & Doorknob & 4.25 & 3.26 & 3.11 \\
\hline Basket & 4.30 & 3.45 & 2.97 & Dresser & 4.52 & 3.75 & 2.92 \\
\hline Bowl & 1.82 & 2.30 & -2.82 & Envelope & 4.12 & 3.30 & 3.09 \\
\hline Button & 2.02 & 1.40 & 3.26 & Eye & 4.88 & 4.30 & 2.82 \\
\hline Cake & 2.88 & 2.20 & 2.73 & Football helmet & 3.15 & 2.23 & 3.09 \\
\hline Candle & 2.48 & 1.80 & 2.66 & Glass & 4.78 & 4.05 & 2.91 \\
\hline Carrot & 2.95 & 2.20 & 3.07 & Hammer & 3.48 & 2.60 & 2.84 \\
\hline Cat & 3.25 & 2.55 & 2.73 & Headphones & 3.65 & 2.64 & 2.85 \\
\hline Celery & 4.25 & 3.58 & 2.70 & Horse & 3.55 & 2.30 & 4.25 \\
\hline Cigar & 3.58 & 2.55 & 3.58 & Ironing board & 3.50 & 2.68 & 2.80 \\
\hline Comb & 2.38 & 1.65 & 3.45 & Key & 4.85 & 4.15 & 2.86 \\
\hline Doll & 4.12 & 3.30 & 2.88 & Knife & 4.45 & 3.60 & 3.10 \\
\hline Door & 3.22 & 2.05 & 4.66 & Leg & 4.65 & 3.85 & 2.77 \\
\hline Flower & 3.25 & 2.50 & 2.71 & Pen & 4.78 & 4.05 & 3.00 \\
\hline Glasses & 2.85 & 2.10 & 3.09 & Pipe & 2.90 & 1.70 & 4.51 \\
\hline Glove & 3.02 & 2.30 & 2.99 & Pliers & 3.38 & 2.32 & 3.82 \\
\hline Hand & 2.98 & 2.10 & 3.17 & Pot & 4.22 & 3.26 & 3.25 \\
\hline Mushroom & 3.12 & 2.40 & 2.82 & Record player & 4.40 & 3.45 & 3.31 \\
\hline Nail & 1.80 & 1.15 & 4.77 & Saltshaker & 4.18 & 3.25 & 3.56 \\
\hline Nailfile & 3.18 & 2.35 & 2.87 & Spinning wheel & 1.18 & 2.08 & -3.70 \\
\hline Pants & 2.22 & 1.65 & 2.69 & Tennis racket & 3.62 & 2.70 & 2.97 \\
\hline Ring & 2.55 & 1.90 & 2.62 & Tie & 3.80 & 2.65 & 3.67 \\
\hline Skunk & 4.72 & 3.85 & 3.44 & Toaster & 4.08 & 3.21 & 2.94 \\
\hline Snake & 4.52 & 3.40 & 3.85 & Train & 4.15 & 3.05 & 3.70 \\
\hline Thimble & 3.35 & 2.49 & 3.30 & Umbrella & 3.95 & 3.15 & 3.04 \\
\hline Tomato & 1.98 & 1.50 & 2.66 & Vest & 3.48 & 2.60 & 3.11 \\
\hline Window & 3.18 & 2.20 & 3.73 & Wheel & 2.22 & 3.25 & -3.35 \\
\hline Means & 2.89 & 2.28 & & & 3.89 & 3.08 & \\
\hline
\end{tabular}


Snodgrass and Vanderwart (1980) pictures. However, when the 12 items that appeared most unlike the Snodgrass and Vanderwart pictures were removed from the PPVT-R analysis, the correlations between complexity and familiarity became more positive, rather than more negative, in both the child and the adult data sets.

To assess the extent to which the greater number of concepts and greater name agreement in the Snodgrass and Vanderwart (1980) pictures, relative to the PPVT-R pictures, were important in producing the negative correlation between complexity and familiarity, the correlation was measured for the subset of Snodgrass and Vanderwart pictures in which $H$ in children was greater than 1 . Although this resulted in a subset of only 68 items, with name agreement even lower on average than the PPVT$\mathrm{R}$ pictures, the correlations between familiarity and complexity were almost unchanged $(r=-.45$ for both the child and adult data sets).

To assess the importance of the more restricted complexity range of the PPVT-R pictures, an analysis was done of those 77 Snodgrass and Vanderwart (1980) items that fell between the values of 2.5 and 3.5 in complexity as rated by children. The resulting correlation between complexity and familiarity was -.30 for the adult data set and -.45 for the children $(p<.01$ for both).

Clearly, the different relationships between complexity and familiarity in the two picture sets is robust, and is not greatly affected by differences in sample size, central tendency, or variability of the rated variables. This strengthens the hypothesis that differences in the way the artists were instructed to draw the two picture sets accounts for the different interrelationships. It is possible that when asked to provide a level of drawing detail consistent with the real-life properties of pictured objects, the judgment of the artist is colored by the artist's familiarity with the object. Instructions to maintain a stable level of drawing detail may be less vulnerable to this source of bias.

One way to explore this relationship further would be to rate digitized photographs of familiar objects against a standard background. If the negative relationship between complexity and familiarity is a product of the artist's representational choices, then the relationship should vanish. On the other hand, if the relationship is a product of the real-life properties of objects, perhaps mediated by the fashioning of implements of low visual complexity for familiar tasks, then the relationships should be maintained.

\section{SUMMARY AND GENERAL CONCLUSIONS}

Although the interrelationships between the rated variables were very similar in the two subsets of pictures we studied, there were meaningful differences. The Snodgrass and Vanderwart (1980) picture set showed a consistent moderately negative correlation between familiarity and complexity in children and adults, whereas the PPVT-R pictures did not show this negative correlation. Subtle differences in the construction of the line drawings prob- ably produced this difference, which underscores the importance of careful analyses of the stimuli used in investigations of pictorial information processing.

Children produced the same modal names as adults for 295 of the 320 pictures. This finding that children and adults show substantial agreement on the names of the pictures is encouraging for studies in which it is desirable to compare pictorial information processing in different age groups. The children rated the pictures lower in name agreement, familiarity, and complexity than did the adults, but these differences were trivial. The strength of the correlations between the ratings of children and those of adults in both picture sets we investigated leads us to conclude that judgments of familiarity, complexity, and, to a lesser extent, the name of line drawings of common objects are based on information processing accomplished before age 7, and are modified relatively little thereafter.

\section{REFERENCES}

Berman, S., Fredman, D., Hamberger, M., Shodgrass, J. G. (in press). Name agreement, familiarity and visual complexity norms for 320 line drawings in children and adults. Social and Behavioral Sciences Documents.

Carroll, J. B., Davies, P., \& Richman, B. (1971). The American heritage word frequency book. Boston: Houghton Miflin.

Carroll, J. B., \& Wite, M. N. (1973a). Age of acquisition norms for 220 picturable nouns. Journal of Verbal Learning \& Verbal Behavior, 12, 563-576.

Carroll, J. B., \& White, M. N. (1973b). Word frequency and age of acquisition as determiners of picture naming latencies. Quarterly Joumal of Experimental Psychology, 25, 85-95.

DunN, L., \& DuNN, L. (1981). Peabody picture vocabulary test-revised. Circle Pines, MN: American Guidance Service.

Hitch, G. J., \& HaldidaY, M. S. (1983). Working memory in children. Philosophical Transactions of the Royal Society of London, B302, 325-340.

Hulme, C., Silvester, J., Smith, S., \& Muir, C. (1986). The effects of word length on memory for pictures: Evidence for speech coding in young children. Journal of Experimental Child Psychology, 41, 61-75.

Kučera, H., \& Francis, W. N. (1967). Computational analysis of present-day American English. Providence, RI: Brown University Press.

Matsukawa, J. (1983). A study of characteristics of pictorial material. Memoirs of the faculty of law and literature: Shimane University. Shimane-ken, Japan: Shimane University.

Schiano, D. J., \& WatkIns, M. J. (1981). Speech-like coding of pictures in short-term memory. Memory \& Cognition, 9, 110-114.

SNOdgrass, J. G., \& VANDERWART, M. (1980). A standardized set of 260 pictures: Norms of name agreement, image agreement, familiarity, and visual complexity. Journal of Experimental Psychology: Human Leaming \& Memory, 6, 174-215.

van Schagen, I., Tamsma, N., Bruggemann, F., Jackson, L. L., * Michon, J. A. (1983). Namen en normen voor plaatjes. Nederlands Tijdschrift voor de Psychologie, 38, 236-241.

\section{NOTES}

1. When the authors of the adult study, Snodgrass and Vanderwart, were kind enough to provide the original drawings, the drawing of the accordion was lost in transit.

2. The response "?" corresponded to the response category "DKO" (don't know object) used by Snodgrass and Vanderwart (1980). The 
response "?name" collapsed the response categories "DKN" (don't know name) and "TOT" (tip-of-tongue) used by Snodgrass and Vanderwart. Pilot testing convinced us that children of this age have difficulty in reliably discriminating the proper occasions for making these two responses.

3. For example, when concepts with two-word names are missing data on frequencies in print, we dropped these cases from the correlations involving the Kưera-Francis (1967) or American Heritage (Carroll et al., 1971) frequency measures. The cases were not dropped from correlations with intact data, such as the correlation between length and name agreement. This results in an input-correlation matrix for the factor analysis with correlations based on different numbers of cases, but it maximizes the use of available data.

\section{APPENDIX}

The 61 PPVT-R pictures in alphabetical order by adult name. Reproduced by permission of American Guidance Service, Publishers' Building, Circle Pines, MN 55014. Peabody Picture Vocabulary Test-Revised by Lloyd M. Dunn and Leota M. Dunn. Copyright 1981. All Rights Reserved.

1

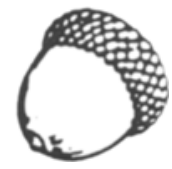

j

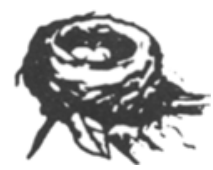

9

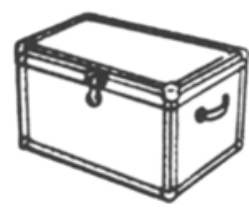

13

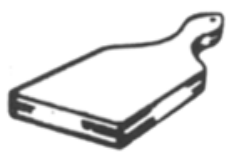

17

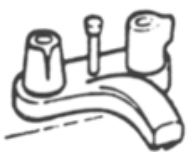

2

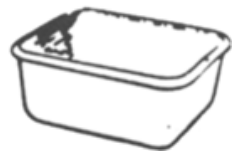

6

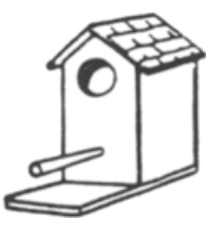

10

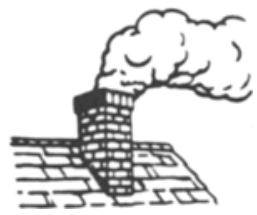

14

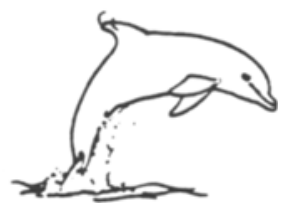

18

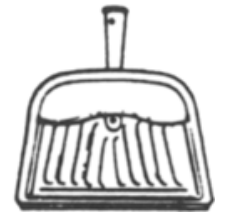

19
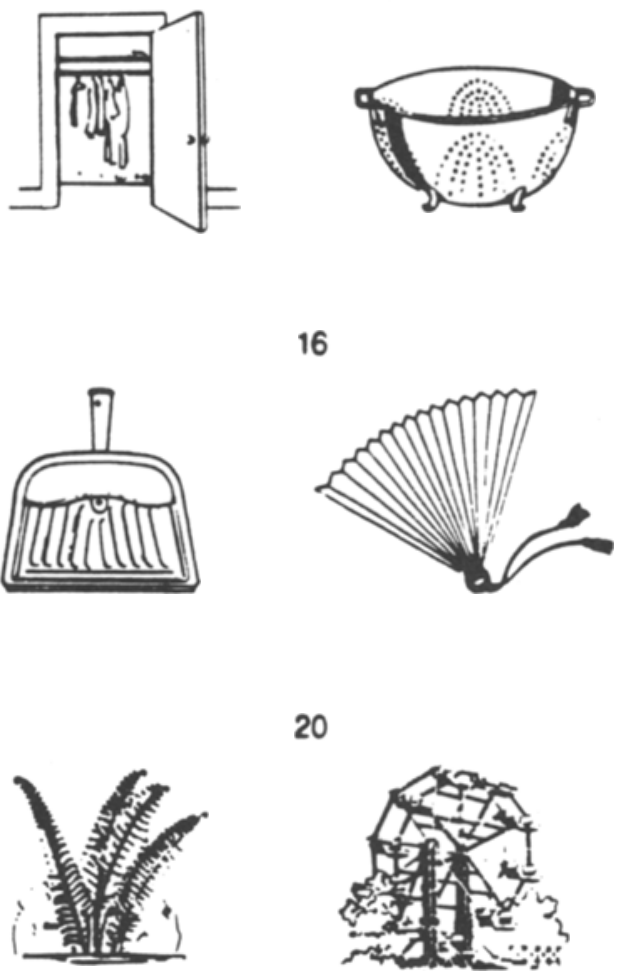

12

16

20

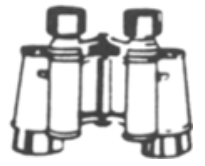

8
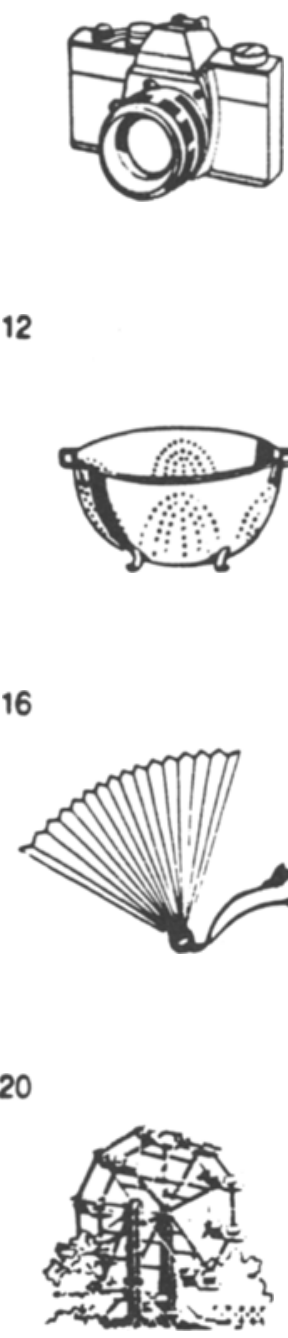
21

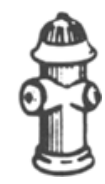

25<smiles>C#CC1CCCCCC1C(=O)O</smiles>

29

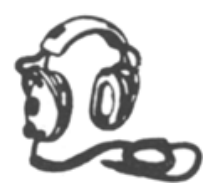

33

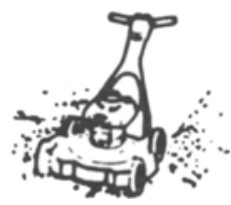

37

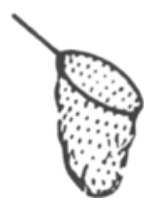

41

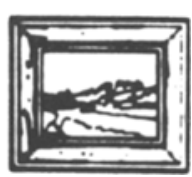

22

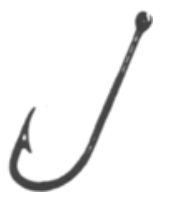

26

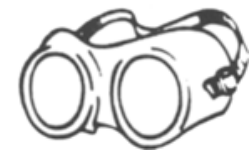

30

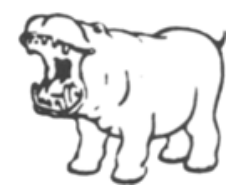

34

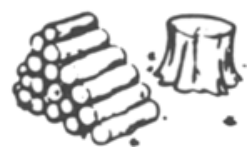

38

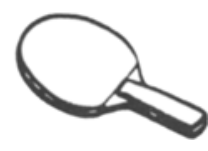

42

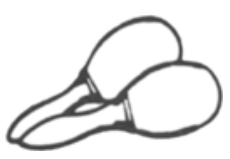

39

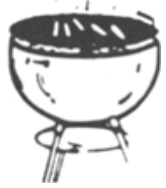

31
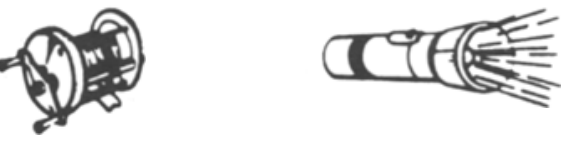

28

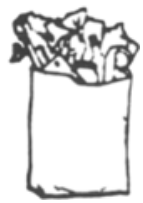

32
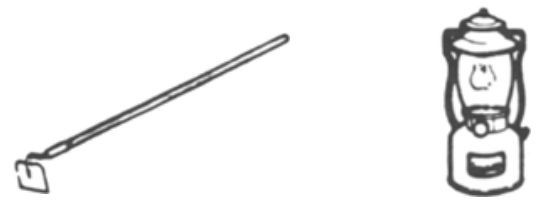

36

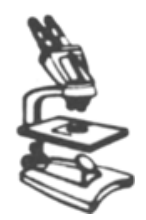

40
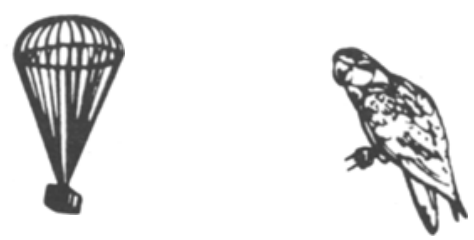

43

44
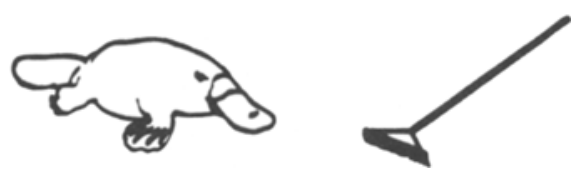
45

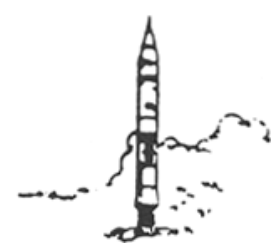

49

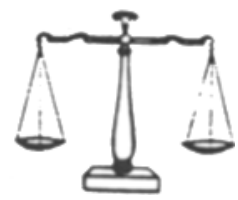

83

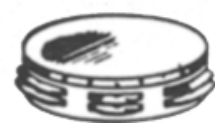

59

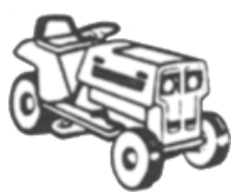

46

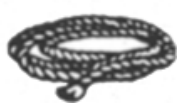

50

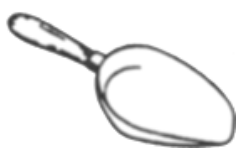

54

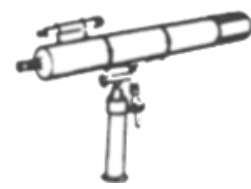

58

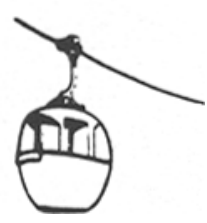

47

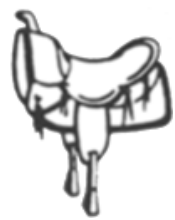

51

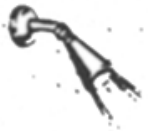

55

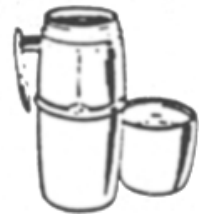

59

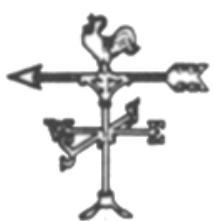

48

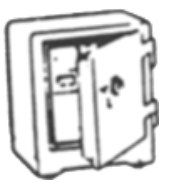

52

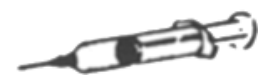

56

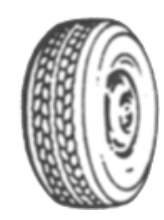

60

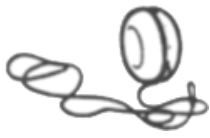

61

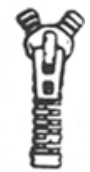

(Manuscript received November 15, 1988;

revision accepted for publication January $27,1989$. 